\title{
Designing an efficient tidal turbine blade through Bio-mimicry: A systematic review
}

\begin{abstract}
Purpose: A comprehensive literature review is conducted in the tidal energy physics, the ocean environment, hydrodynamics of horizontal axis tidal turbines, and bio-mimicry.
\end{abstract}

Design/methodology/approach: The paper provides an insight of the tidal turbine blade design and need for renewable energy sources to generate electricity through clean energy sources and less $\mathrm{CO}_{2}$ emission. The ocean environment along with hydrodynamic design principles of a horizontal axis tidal turbine blade are described, including theoretical maximum efficiency, Blade Element Momentum theory, and nondimensional forces acting on tidal turbine blades.

Findings: This review gives an overview of fish locomotion identifying the attributes of the swimming like lift based thrust propulsion, the locomotion driving factors: dorsal fins, caudal fins in propulsion, which enable the fish to be efficient even at low tidal velocities.

Originality/value: Finally, after understanding the phenomenon of caudal fin propulsion and its relationship with tidal turbine blade hydrodynamics; this review focuses on the implications of bio-mimicking a curved caudal fin to design an efficient Horizontal Axis Tidal Turbine.

KEY WORDS: Bio-mimicry, Horizontal Axis Tidal Turbine, Ocean Environment, Tidal Energy.

\section{INTRODUCTION}

Currently, global energy requirements are met by consumption of fossil fuels. As the heavy dependence on fossil fuel increases it is becoming a primary concern and countries worldwide, have now realised the need to incorporate renewable energy sources into their energy policies as an alternative to fossil fuels (Morandi et al., 2016). Tidal energy is a renewable electricity source based on the conversion of kinetic energy of moving water into mechanical power to drive generators (Shi et al., 2015). It has fewer $\mathrm{CO}_{2}$ emissions, it has minimal reliance on fossil fuels, and is one of the many sources to address concerns over climate change (Tedds et al., 2014). As there is a need to identify and use more sustainable sources of power generation tidal energy will gain more attention. Tides result from the gravitational pull of the moon. "As water covers $71 \%$ of the earth's surface, energy can be harnessed on a large scale through tides" (Blunden and Bahaj, 2006). Tides are predictable, which is also the greatest advantage that tidal energy has over other renewable sources like wind or solar power.

As a result of this growing interest in tidal energy, many new tidal turbine blade designs have been created. Tidal turbines are classified into two type's horizontal axis tidal turbines (HATT), and vertical axis tidal turbines (VATT) (Uihlein and Magagna, 2016). HATT are also known as axial flow turbines; they have the rotational axis parallel to the tidal flow; thus, they operate in only one flow direction (Magagna and Uihlein, 2015). The principle of operation of the HATT is similar to the horizontal axis wind turbine (HAWT); it has blades fitted to the hub, a generator to convert kinetic energy from the water to mechanical energy, shaft to produce power and gearbox (Bai et al., 2016).

Bio-mimicry or biomimetic has proved to be an excellent motivation to solve complex human problems, by imitating nature (Fish et al., 2011). The design process starts by looking at nature's ecosystem, selfhealing abilities or a particular organism, to produce a design solution to the human need. The classic example of the bio-mimicry is the Humpback Whale wind turbine, designed adapting the whale's flippers and tubercles (Fish and Battle, 1995) (Shi et al., 2016). The locomotion of the marine vertebrate is based on the five fins namely; caudal, anal, pelvic, pectoral, and dorsal fins which are located around its body, and the movements caused because of these flexible fins act as the main source for propulsion at high swimming efficiency (Chang et al., 2015). As $80 \%$ of the propulsive efficiency i.e. the swimming speed for e.g. Blue Marlin fish is caused due to its high lift generating caudal fin, which makes it one of the fastest propelling fishes under the ocean, and also enables it to be efficient even at the low velocities (Chiang et al., 2015; Su et al., 2016). 
The aim of this review is to provide an insight over the implications of bio-mimicking a curved caudal fin to design an efficient HATT in the field of tidal energy. As well as, it combines the aspects of the tidal energy physics, the ocean environment, hydrodynamics of horizontal axis tidal turbines, and bio-mimicry (through marine vertebrate synopsis). The article is structured as follows: Section 2 presents the tidal energy physics and tidal energy resources in the UK; Section 3 will present the ocean environment and tidal flow analysis methods. Section 4 covers hydrodynamics of tidal turbines, and Section 5 bio-mimicry and its applications. Finally, conclusions of this review are presented in Section 6.

\section{TIDAL ENERGY PHYSICS AND ITS APPLICATIONS}

Tides are the results of rotational movements within the gravitational and centrifugal forces of the sun and the moon. Two high and two low tides pass through a point on the equator, approximately because the moon rotates through the centre of the earth-moon system during this time; this cycle is never ending. Hence, tidal energy is renewable energy. The fundamental lunar patterns in seawater energy are defined as follows (Rayson et al., 2015):

- Lunar day: The time for a cycle of two high and two low tides is 24 hours and 50 minutes per tidal day, known as a lunar day in seawater energy context.

- Synodic or Lunar Cycle: The period from full moon to full moon is 29.53 days, known as Synodic or Lunar month.

- Diurnal tides: One high and one low tide per tidal day. The period is 24 hours and 50 minutes.

- Semi-diurnal tides: Two equal high tides and two similar low tides per tidal day. The period is 12 hours and 25 minutes.

- Spring tides: At the full moon, the moon is in between sun and earth, during this period, sun's gravitational field is in the same direction as the moon. At this time, the high tides are higher and low tides are lower known as Spring Tides (Iwasaki et al., 2015). Spring tides are larger because tidegenerating forces of sun and moon are combined.

- Neap tides: During the first or last quarter of the moon, the sun's gravitational forces are perpendicular. There is a partial cancellation of the tide-generating forces resulting in lower high tides and higher low tides known as Neap tides (Yuce and Muratoglu, 2015). Generation of the neap tides and spring tides is demonstrated in Figure 1.

Figure 1 Generation of the neap and spring tides (James et al., 2010)

\section{Tidal energy resources in the $U K$}

There are significant efforts put in by the UK government to meet the 2020 target of having $15 \%$ renewable energy which would reduce $34 \%$ of the CO2 emissions (Konadu et al., 2015). To achieve these targets, major investment is necessary, given the UK's vast tidal energy resource. Due to the geographical advantage of the UK, it is a world leader regarding tidal energy potential resources, which could provide power up to $50 \mathrm{TWh} / \mathrm{annum}$ (Martin-Short et al., 2015). Black \& Veatch (Black \& Veatch Consulting Ltd, 2005) identified the largest tidal energy sites in the UK where places like the Pentland Firth and the Orkney Islands have tidal current velocities (Spring tides) up to $4.5 \mathrm{~m} / \mathrm{s}$ (Department of Business, Enterprise and regulatory reform, Atlas of the UK marine renewable energy resource, BERR, London, 2008). Figure 2 shows the spring tide currents and their speeds.

Figure 2 Mean Spring tide current velocities and specific regions of tidal sites (Department of Business, Enterprise and regulatory reform, Atlas of the UK marine renewable energy resource, BERR, London, 2008).

Iyer et al., (2013) suggest that the tidal energy sites would potentially produce $35 \mathrm{TWh} / \mathrm{year}$ of power through tidal turbines/devices per year. The Pentland Firth alone has the installation capacity of $4532 \mathrm{MW}$ of power output with total power output potential being $9.7 \mathrm{GWh} / \mathrm{year}$ (Easton et al., 2012). There is no doubt, that if this technology was developed to its full potential, it would help the 
UK Government in achieving its 2020 renewable energy targets and would not compromise the energy demand for the future.

In the UK, the Pentland Firth is an area which meets all the above generic criteria for a site selection. It connects to the North Atlantic and lying in the South of Orkney Islands (Scotland, UK). The Pentland Firth is known for experiencing spring tide current velocities up to $7 \mathrm{~m} / \mathrm{s}$ with power generation capacity approximately of $1 \mathrm{GW}$ over the year. "The Pentland Firth is around $23 \mathrm{~km}$ long and varies in depth from $60 \mathrm{~m}$ to $100 \mathrm{~m}$ along its main axis. Its width varies considerably, with $7.5 \mathrm{~km}$ being taken as representative of the width of the region of high flow along the Firth. Maximum flows can exceed $4.5 \mathrm{~m} / \mathrm{s}$ in some locations within the Firth at spring tides" (Vennell, 2013). Although a tidal site might experience higher tidal current velocities, the velocities are not continuously high; they vary throughout the year. Figure 3 shows the tidal current velocities in mean spring tide for the Pentland Firth, Scotland area.

Figure 3 the tidal current velocities in mean spring tide for the Pentland Firth, Scotland area (Shields et al., 2009)

Bryden et al., (2007) generated water flow velocity graphs using UK Admiralty charts and Marine Atlases around the Pentland Firth, UK. The tidal flow velocities range from 1 to $3.5 \mathrm{~m} / \mathrm{s}$ for the annual spring and neap tides around the Pentland Firth, Scotland, which varies throughout the year. Bryden and Couch (2006) demonstrated how the mean energy flux behaves in a tidal channel which has a width of $1000 \mathrm{~m}$ and depth of $40 \mathrm{~m}$ for the mean neap tide and assuming the peak spring tide of $3 \mathrm{~m} / \mathrm{s}$. They reported that the performance of the tidal rotor to harness the electricity, and the turbine efficiency depends on the water flow velocity and its variation.

\section{Types of tidal turbines}

There are two types of tidal turbines: 1) Horizontal axis tidal turbines (HATT) and 2) Vertical axis tidal turbines (VATT), of which HATT's are the most efficient ones. The working principles of tidal turbines are similar to wind turbines, but sea water is nearly 835 times denser than the wind (Cai et al., 2012). As the tidal turbines are submerged the working conditions are different from the wind energy environment, tidal turbines experience more forces and pressure than wind turbines. Due to these reasons, tidal turbines can have smaller blades and rotate slower than but can still capture the same amount of the kinetic energy to produce power. Flow under seawater cannot be unidirectional like the wind; it can be bidirectional (Waters and Aggidis, 2016). Tidal turbines are capable of reversing their blades to suit the flow from any direction; it can be done by changing the blades and by having a pitch of $180^{\circ}$ to generate electricity on both flood tide and ebb tide. A sample of HATT applications including the curved HATT is discussed below.

i) The Marine Current Turbine (MCT), UK: The largest developer of full-scale horizontal axis tidal turbines in the UK is MCT (Elghali et al., 2007). MCT have developed two technologies which are explained below:-

a) Seaflow: Seaflow turbine system has an $11 \mathrm{~m}$ diameter turbine with a power output of $300 \mathrm{~kW}$. It has a complete span pitch control to face flow from any direction. It is installed at Foreland Point in North Devon, UK. Its significant feature is that it is not connected to the grid but is fixed on a tubular pile, and the entire turbine can be raised up for maintenance (MCT, 2008). Figure 4 demonstrates the Seaflow turbine system.

Figure 4 Seaflow turbine system by MCT (MCT, 2008)

ii) Swept Twist Adaptive Rotor (STAR) Blade: Sandia National Laboratories (SNL) partnering with Knight and Carver $(K \& C)$ modelled a horizontal axis wind turbine called the Swept Twist Adaptive Rotor (STAR) blade aiming to improve annual power production from low wind velocity sites (Ashwill et al., 2010). The entire STAR project was funded by the US Energy Department's 'Wind and Water Program' to promote energy generation from the wind from lower wind velocity areas. The STAR blade was inspired from a 'high lift generating bird feather' allowing the geometric 
sweep for longer blade fatigue life (Larwood and Zuteck, 2006). After conducting the parametric design of the STAR blade, an aeroelastic analysis was done to fabricate the modelled blade. The operating loads and the power output were calculated using 'full flight tests' achieving their primary goal of improving the annual power output by 10 to $12 \%$. The design variables utilised for the optimisation process were planform, airfoil thickness, sweep magnitude, airfoil and blade structural geometry; root airfoil forward sweep angle and load reduction at the root airfoil station. Figure 5.1 shows the swept blade artistic concept from the 'high lift generating bird feather', and Figure 5.2 shows the manufactured STAR blade for flight testing.

Figure 5.1 Swept blade concept (after Ashwill et al., 2010), Figure 5.2 Manufactured STAR blades for flight testing

(Larwood and Zuteck, 2006)

\section{THE OCEAN ENVIRONMENT}

\section{Maximum theoretical power generation}

The available power in a flow of water can be calculated as the kinetic energy per unit time passing through the cross-sectional area of the rotor. Therefore the available power for a tidal turbine can be calculated by using Equation 1 and the derivation follows (Mycek et al., 2013):

Assuming constant linear acceleration,

And,

$$
\begin{gathered}
v^{2}=u^{2}+2 a x \\
v^{2}=2 v \cdot \frac{d v}{d x} \cdot x \\
\therefore \frac{d v}{d x}=\frac{v^{2}}{2 x}
\end{gathered}
$$

$$
\begin{aligned}
P & =F \cdot V \\
& =M \cdot \frac{d v}{d t} \cdot V \\
& =M \cdot \frac{d v}{d x} \cdot V^{2} \\
& =\rho V \cdot \frac{\frac{1}{2} v \cdot}{x} \cdot V^{2} \\
P & =\frac{1}{2} \rho A V^{3}
\end{aligned}
$$

Eqn. 1

where $\mathrm{P}$ is available to power $(\mathrm{W}), \rho$ is water density $\left(\mathrm{Kg} / \mathrm{m}^{3}\right)$, $\mathrm{A}$ is the cross-sectional area perpendicular to water $\left(\mathrm{m}^{2}\right), \mathrm{V}$ is water velocity $(\mathrm{m} / \mathrm{s})$.

Tidal turbines and wind turbines share the same working principle. Although all the kinetic energy is available for power production, Betz's law states that the maximum efficiency of a turbine is $59.3 \%$ (Betz, 2014). Keck and Sick (2008) suggest that to allow variable speed operation; the mechanical rotor speed and the frequency of the electric supply grid must be decoupled. When the water velocity increases to levels above the water flow velocity, the power generated cannot be increased further, because this will lead to overloading of the generator. Therefore, the hydrodynamic efficiency of the tidal rotor must be reduced, to limit the power extracted from water to the maximum power of the tidal turbine. Vu and Retieb (2002) showed efficiencies of various tidal turbines in Figure 6.

Figure 6 various efficiency limits of water turbines (after Vu and Retieb, 2002)

Tidal flow analysis methods 
Tides are produced by the gravitational interactions of the sun and moon which act on the ocean. Elevations of tides only occur when there is a rise in oscillating forces produced by oceanic tides on the shallower continental shelf. It is assumed that tidal stream processes should have same analytical properties, hence to provide a good tidal flow analysis for a location; traditionally harmonic analysis of tides has been preferred especially for the ups and downs of the tides in "shallow water" areas (Arns et al., 2013). The tidal waves are not directly influenced by gravitational/astronomical effects between the sun and the moon along the coastal and shallow water areas. The positions of the sun, the moon and the earth are not circular but elliptical due to this reason they all are inclined to each other and result in different lunar periods and cycles. The principal lunar periodicities and lunar forces for the sun-moon-earth system are discussed below:

a) Smaller periodic lunar cycles: In the oceanographic context, when the orbital plane of the moon is inclined with the earth's equatorial plane it results in tidal force generation and the moon is in the elliptical orbit of the sun-moon-earth system. At this time, the moon has maximum declination and the variations of the declinations during this period is called as a tropical month which has the same rotation as earth and the length is 27.32 days. The period of time from new moon to new moon is called as the synodic month and the duration of that month is 29.53 days (Adrian and Meeuwig, 2001).

b) Longer periodic lunar cycles: When the earth revolves around the sun in an elliptical orbit, the length of time on earth's rotation is 365.2422 days. When the moon's orbit intersects the earth it has an angle of $5.15^{\circ}$ to the lunar plane of sun's elliptic path. At this period, the moon's orbit rotates slowly in that plane, the length of this period is 18.61 years which is also known as "the lunar node revolution" (Lowry et al., 2007). The last concept of the longer periodic cycle called "The Perihelion cycle", at this period the earth's orbit faces the effects of the earth's revolution around the sun which is very slow at this period and the length is 20940 years. The sun has similar periodic cycles.

1.1.1 Harmonic analysis: Leffler \& Jay (Leffler and Jay, 2009) reported the need for analysis and understanding of the tidal behaviour because of the dynamic nature of coastal and estuary waters. They also indicated that taking measurements for a longer period of tidal action with appropriate accuracy is required for the prediction of tides. Traditionally, the astronomical effects on tides have been analysed by using harmonic analysis method (Foreman and Neufeld, 2015). While explaining the tides local bathymetry and the topology of the location are paramount to the forces acting on the tidal constituents. A harmonic analysis of tides allows measuring of the periods, amplitudes, frequencies, and different phases of a tide at a particular location, by mapping a curve called "Nyquist frequency" (Matte et al., 2014).

1.1.2 Response analysis: The response analysis of the tides is more precise than the traditional harmonic analysis of tides and has greater accuracy with analysing fewer tidal constituents (Crawford, 2015). The mathematical formulation of the response method was done by Groves \& Reynolds (Groves and Reynolds, 1975), treating the seawater as an equilibrium system with tides as the input and tide flow velocity as the output.

Despite the response method being more accurate and precise than the harmonic analysis method for tides, it can also operate in shallow waters with low gravitational effects; the harmonic analysis remains the preferred method for analysing the tides because of its ease of computer analysis and simple conceptual understanding (Zetler et al., 2015).

\section{HYDRODYNAMICS OF TIDAL TURBINES}

\section{Blade Element Momentum theory}

Tidal turbine power generation depends on the interaction between the sea water and tidal turbine blade. Betz (2014) demonstrated the simple idealised model of ideal turbine, with ideal flow of fluid. 
This model of linearized blade momentum theory was developed in early 1920's to measure the performance of ship propellers. Malki et al., (2013) suggested that using BEM method loads and the thrust of the rotor blade can be calculated for various velocities, angular velocity and pitch angle. They demonstrated that a blade could be divided into $\mathrm{N}$ number of sections with assuming that each section is independent of other sections, and lift and drag on each section of the airfoil section define the force acting. Figure 7 demonstrates various sections in a rotor blade and its angular velocity.

Figure 7 Illustration of the blade sections (after Manwell et al., 2010)

where $\mathrm{c}$ is airfoil chord length or is the radial length of the blade section $(\mathrm{m}), \mathrm{r}$ is the rotor radius $(\mathrm{m})$, and $\Omega$ is the angular velocity of the rotor $(\mathrm{rad} / \mathrm{s})$

This theory it assumes the tidal rotor as the actuator disc and tidal rotor in a control volume (CV) boundaries (Figure 8). BEM theory is based on the following assumptions:

- The fluid flow should be steady, homogeneous and incompressible,

- The turbine disc has an infinite number of blades, with velocity being constant in the rotor area,

- The turbine should not produce any wake or rotational flow,

- The flow should not get obstructed either by downstream or upstream boundaries i.e. the static pressure should be equal to the ambient static pressure distributed across the control volume.

Figure 8 Flow velocity in a control volume according to actuator disc theory (after Eggleston and Stoddard, (1987)

where $\mathrm{S}$ is the control volume cross-sectional area $(\mathrm{m}), \mathrm{P} 0$ is the ambient pressure of the atmosphere $(\mathrm{N} / \mathrm{m} 2), \mathrm{V} 0$ is the fluid velocity at inlet and outlet of $\mathrm{CV}(\mathrm{m} / \mathrm{s}), \mathrm{u}$ and $\mathrm{u} 1$ are the downstream and upstream fluid velocity of the $\mathrm{CV}(\mathrm{m} / \mathrm{s}), \mathrm{P} 2$ and $\mathrm{P} 3$ are the downstream and upstream pressure of the rotor $(\mathrm{N} / \mathrm{m} 2), A$ is the area of the rotor $(\mathrm{m} 2), A 0$ and $A 1$ are the areas of the inlet and outlet cross section of the tube.

As the water is moving towards the rotor plane area, Bernoulli's pressure theorem assumes that "the flow is frictionless". The atmospheric pressure is usually about 1atm which is equal to $101325 \mathrm{~Pa}$, and assuming that density of the fluid is constant, the upstream and the downstream pressure can be defined using Equations 2 and 3 respectively:

$$
P_{0}+\frac{1}{2} \rho V_{0}^{2}=P_{3}+\frac{1}{2} \rho u^{2}
$$

Eqn. 2

and

$$
P_{2}+\frac{1}{2} \rho u^{2}=P_{o}+\frac{1}{2} \rho u_{1}^{2}
$$

Eqn. 3

Thus the axial force (thrust, $\mathrm{T}_{\text {rust }}, \mathrm{N}$ ) can be defined as:

$$
T_{\text {thrust }}=\frac{1}{2} \rho A\left(V_{0}^{2}-u_{1}^{2}\right)
$$

After defining the axial force in the tidal turbine, axial interference factor can be defined as minute decrease in the water velocity in the free stream and rotor plane,

$$
u=V_{0}(1-a)
$$

Eqn. 5

It is now possible to define the lift coefficient for a tidal turbine blade which can be expressed as: 


$$
C_{L}=\frac{L}{\frac{1}{2} \rho V^{2} A}
$$

Eqn. 6

The drag coefficient for a tidal turbine blade is defined as:

$$
C_{D}=\frac{D}{\frac{1}{2} \rho V^{2} A}
$$

Eqn. 7

and the pitching moment (torque) coefficient for a tidal turbine blade can be defined as:

$$
C_{M}=\frac{M}{\frac{1}{2} \rho V^{2} A}
$$

Eqn. 8

where, $\rho$ is the density of the sea water $\left(\mathrm{kg} / \mathrm{m}^{3}\right), \mathrm{V}$ is the non-uniform velocity of sea water $(\mathrm{m} / \mathrm{s}), \mathrm{A}$ is the area of turbine blades $\left(\mathrm{m}^{2}\right), \mathrm{M}$ is the torque (N.m).

Tidal turbine is distinguished by its power coefficient $C_{P}$ which can be defined as follows:

$$
C_{P}=\frac{P}{\frac{1}{2} \rho V^{3} A}=\frac{\text { Turbine Power }}{\text { Power in the sea water }}
$$

Eqn. 9

To obtain an optimal $C_{P}$, Betz limits $16 / 27$ or 0.593 should be considered while calculating the power coefficient with an axial interference factor giving $\mathrm{a}=1 / 3$ or 0.33 , then $P_{\text {Betz }}$ can be calculated as:

$$
P_{B e t z}=C_{P B e t z} \frac{1}{2} \rho V^{3} A
$$

Eqn. 10

where, $P_{\text {Betz }}$ is the optimal power that can be produced by a tidal rotor $(\mathrm{W}), C_{P B e t z}$ is the Betz limit power coefficient $(16 / 27)$.

\section{BIO-MIMICRY AND ITS APPLICATIONS}

Biomimicry is a field which studies nature, and later imitating its designs and models to solve complex human problems (Benyus, 1997). The design process starts by looking at nature's ecosystem, self-healing abilities or a particular organism, to produce a design solution to the human need (Michaels et al., 2015). To enable an optimal tidal turbine blade creating higher efficiency throughout the year, swimming speeds of the marine vertebrates are studied including their characteristics which allow swimming and providing highest propulsion efficiency. This section also includes a brief study of the fish locomotion which identifies the attributes of the swimming like lift based thrust, the locomotion driving factors: dorsal fins, caudal fins in propulsion, which enable the fish to be efficient even at low tidal velocities.

\section{Existing applications}

The analysis of the lengths, and weights of fish species like Swordfish, and Sailfish have been performed by Lenarz and Nakamura, (1972), but the concept of using nature to solve complex human problems is a recent idea. The classic example of this is the Humpback Whale and Wind turbine blades (which is discussed below), and also the underwater propellers, which are the two 
most prominent marine and fish locomotion application, which directly relates to the aerodynamics, and thus are now being used to design modern wind turbines and marine propellers.

\section{Humpback whale and Wind turbine blades}

The primary application of the marine vertebrates and their locomotion was first explored by Dr Frank Fish, to design an efficient wind turbine blade adapting Humpback Whale's flippers and tubercles, in a Toronto-based company called WhalePower (Leung, 2014). The authors proposed this new design of humpback whale wind turbine blade design and also claimed that their design gives $20 \%$ extra annual power production as compared to other existing wind turbine blades, and also has a delayed stall (Fish et al., 2011). Figure 9.1, and Figure 9.2 illustrated the humpback whale pectoral flippers and manufactured adapted tubercles on the leading edge of the wind turbine blade.

Figure 9.1 Humpback whale pectoral flippers, and Figure 9.2 Manufactured adapted tubercles on the leading edge of WhalePower wind turbine blade (Fish et al., 2011).

Dr Fish also claimed that introducing the tubercles at the tip of the blade forces air flow to decrease the turbine noise, and it works smoothly with less vibration and noise. The tubercle wind turbine blade accomplished the pitch angle of $28^{\circ}$, at the same inlet wind velocity, when compared to the traditional wind turbine which produces the pitch angle of $16^{\circ}$. Their study concluded with conveying " $20 \%$ gain in the overall efficiency and reducing $1 / 5$ th of the vibrational noise in the tubercle wind turbine blade design" (Fish, 2009).

\section{Underwater Propellors}

Underwater propellers are designed and developed for a broad range of marine applications like boats, ships, and submarines. Underwater propeller systems are used to travel long distances, and traditional propeller designs are only designed for two design constraints: maximum velocity which allows the submarines to travel long distances, and low velocity rotating propellers allowing limited range transportation. Thus there is a gap in between these two realms, and there is a need for better propulsion mechanisms (Liu and $\mathrm{Hu}, 2005$ ). The underwater propulsion converts rotational shaft power to thrust propulsion, and thus the propulsion of the underwater vehicles is solely based on the control surface and thrust generation mechanism. The propulsion efficiency depends on the rotation of the propeller, and the majority of the propeller losses are incurred as the propeller only rotates in the flow direction, thus by designing the propeller for higher thrust efficiency automatically reduces the drag and improves the manoeuvre of the underwater systems.

Many designers have investigated the benefits of the biomimetic underwater propulsion mechanisms through the thrust characteristics of the fishes like dolphins and tuna fish tail fins, to contribute better efficient propellers for both high and low design speeds. United States Navy, has heavily invested in the research of mimicking the tuna fish tail fin to design a highly efficient submarine termed as 'Faux Fish', which is demonstrated in Figure 36.2. The Faux Fish, submarine propulsion design system is now patented and owned by United States Navy, and the empirical results achieved remain highly confidential (Gieseke Thomas, 2004). Figure 10.1 shows a conventional seven blade marine propeller, and Figure 10.2 illustrates the Faux Fish. 


\section{Work Input vs. Output}

Work input by a fan can be defined as the inward force acting through the distance of entry, whereas work output is the output force acting through the output distance dependent on the force to increase the output distance, by the turbine blades. Fans transfer energy into a flow and thus reducing the pressure, i.e. power is input to fans and output from turbines. Fans for e.g. axial compressors use "back sweep" in the 1D design phase, and the blade twist angles are different on the compressor leading, and trailing edge and the gases can reach higher velocities and energy levels. Thus, fans are not limited by the Betz limit and can have higher efficiencies than 58.3\%. In the case of tidal turbines, the seawater rotates the turbine blades, and the water is pulled out and replaced with the outside water. Fans offer high peak efficiency over wide range of rotational speed range, they have low starting power requirements and have increased pressure rise due to increased number of stages with negligible loss. Thus, bio-mimicking the fans would be a good idea to design a horizontal axis tidal turbine blade as the seawater velocity varies throughout the year, and the tidal turbine blade would have high peak efficiency throughout the year; it would also have increased rotational velocity.

The above-mentioned bio-mimicry examples contribute excellent evidence in improving the functioning and the efficiency of the conventional designs and thus generating entirely new designs. The following section examines the underwater fish locomotion concepts and their characteristics which enable fast and efficient swimming speeds.

\section{Marine vertebrates and their characteristics}

\section{Locomotion and anatomy of marine vertebrates}

The swimming and locomotion characteristics of marine like most other mammals differ in size, weight, shape. Nonetheless, they all live and survive in the unsteady currents in the ocean. Thus certain marine vertebrates function accurately in unsteady and fast seawater currents like Sailfish, Istiophorus Platypterus which is the fastest fish with swimming speeds recorded up to $110 \mathrm{~km} / \mathrm{h}(70 \mathrm{MPH})$, whereas the Blue Marlin fish, Makaira nigricans swimming speed has been recorded up to $80 \mathrm{~km} / \mathrm{h}(50 \mathrm{MPH})$, thus these marine vertebrates employ the thrust manoeuvring or in other words they use their 'fins' for the propulsion (Hoolihan, 2005).

The locomotion of the marine vertebrates is based on the paired fins which are also known as pectoral flippers, caudal fin, dorsal fins or flukes, which enable highest swimming propulsion efficiency (Watanabe and Sato, 2008). For these reasons, these fish prove an excellent motivation for bio-mimicking nature to produce an improved tidal turbine blade throughout the season. The fish caudal fin in profile looks like a streamline, and these fish come in flexible fin shapes and sizes, which makes them adaptable to unsteady marine currents.

The pectoral contribute to the manoeuvrability to swim at low-velocity marine currents, with 'the caudal fin' causing the essential thrust for propulsion (Tokić and Yue, 2012). The caudal fin propulsion may represent a ship is rudder at high speed or an aeroplane movement operating with the same forces like pitch and thrust, including the transfer mechanisms like drag and lift (Kraus et al., 2011). The pressure related forces drag and lift originate due to the water flow acting on the fish body. This propulsion is also termed as the Body and Caudal Fin (BCF) propulsion (Figure 11), which may cause surface area increment or decrement; thus, the swimming movements may differ from species to fish species.

\footnotetext{
Figure 11 the locomotion forces acting on the fish while swimming (Sfakiotakis et al., 1999)
}

Pectoral fins are located at the 'ventrolateral margin' of the fish body and vary in size, shape and function amongst different marine vertebrates as demonstrated in Figure 12. 
The fundamental role of the pectoral fin is generating dynamic lift which allows fishes like sharks to maintain manoeuvrability at certain depths, and thus the dexterity to survive (Drucker and Lauder, 2003). The pectoral fins automatically adjust the angle of attack of the flow to create upward lift, thus act like an easy fish propulsion fin.

Dorsal fins are the easiest to locate in marine vertebrates as they are found in the dorsal part of the spinal cord in fish. The dorsal fins protect the fish from rolling, and help in turning, thus controlling the body at low speeds or to a complete stop (Jayne et al., 1996). The anal fins are located ventrally in the anus region of the fish, and help to manage the body orientation to maintain the stability when the swimming velocity increases (Standen and Lauder, 2007). Figure 12 illustrates the evolution of the pectoral fins in different fish species.

Figure 12 the evolution of the pectoral (A), and dorsal (B) fins in different species (Jayne et al., 1996)

The caudal fin, which is also termed the tail fin, is located at the end of the fish's body (caudal penuckle), and is the main fin that produces thrust propulsion through seawater. The caudal fin like pectoral fins come in various shapes, and sizes in different species. The caudal fin oscillates with the horizontal movements to produce the propulsion efficiency by accelerating the body forward in the seawater (Cho et al., 2008). The caudal fin based propulsion is caused due to the undulation in the fish body, and this is represented by the Body Caudal Fin (BCF) propulsion. The undulatory swimming locomotion is divided into the following sections (Windsor et al., 2010a) and is demonstrated in Figure 13.

1) Anguilliform: In this type of undulatory swimming, the fish completes one wavelength with their entire body i.e. swimming is possible via both forward and backwards movements for fishes like eels, and other jawless fishes.

2) Carangiform and Subcarangiform: The undulatory fish locomotion in this type is performed similarly to the Anguilliform type, but these two types also form the hybrid type of swimming locomotion, due to $75 \%$ of the body being used to propagate the wave amplitude. The caudal fin thrust propulsion of this type is usually seen in trout (Windsor et al., 2010b).

3) Thunniform: This type of swimming mode is the more potent and efficient marine vertebrate locomotion which is lift based thrust generation occurring due to the caudal fin. The evolution of Thunniform locomotion is found in sharks, marine mammals and other fishes; this thus allows the marine vertebrates to maintain fast swimming under low water velocities as well. In the Blue Marlin fish the thrust propulsion is $80 \%$ efficient based on the caudal fin, and despite swimming at high speed, its body is optimised for efficient locomotion in calm waters, as well as turbulent waters.

Figure 13 Different swimming modes of fishes (Sagong et al., 2013)

\section{Justification of the fish selection}

Biomimicking is a prominent trend in the aerospace industry, as morphing the aircraft wing design continues to change based on the shapes of bird's wings (Abdulrahim and Lind, 2004). Modern aircraft designs are specifically morphed to make them highly adaptable to produce maximum lift and twisted for drag reduction for e.g. when Eagles (Figure 14) are observed in the flight their wings are broadened when they are high in the sky, and when they are gliding their wings attempt to reduce the drag and thus increase the lift. By using the bird wing morphing principles, the aircraft wings are highly adaptable to highly unsteady, time-differing, and uncertain dynamics, which also 
causes weight reduction and wingspan gaining enough lift and thrust (Han et al., 2009). The Progress Eagle (US Army conventional UAV) uses ultralight materials in its designs, uses solar energy during flight and is also an example of bird morphing.

The aerospace industry inspires the wind turbine industry for turbine blade design. Airfoil theory is used to develop fixed wing aircraft, while Helicopter blades and Wind turbine blades are designed using a more complex Blade Element Momentum theory to predict the aerodynamic forces. Helicopter blades which are stiff and have high aspect wing ratio rotate at a high speed to produce enough force. As illustrated in Figure 14, Whale humpbacks have recently inspired the creation of bio-mimicked helicopter and wind turbine blades to reduce the skin friction, and drag (Bhushan, 2009; Canter, 2008). Thus, morphing the blade shapes to a humpback tubercles increased the efficiency of the blades by additional $20 \%$, compared with the standard blade types in both the cases. Other examples which are inspired by aquatic animals are robotic fish (gold shiner fish inspiration), and school fish movement to understand the complex fish swimming in the water currents, and Lilly Impeller (Nautilus shell inspiration) for energy efficient water mixing in the storage tanks.

Marine vertebrates have the functionality to force their bodies throughout the ocean, and with the help of their fins, they create lift and thrust based propulsion as the water currents advance through their body (Flammang, 2014). As illustrated in Figure 12, the fins of a marine vertebrate evolve to increase the efficiency while swimming, with the caudal fin at particular angles decreasing the drag force, thus resulting in lift increment (Salumäe and Kruusmaa, 2011). The advantage of the drag decrement at the effective angles of a caudal fin is the ability of the marine vertebrate is to push its body through the water currents at acute angles without losing the ability of propulsion (Gleiss et al., 2011). The increment in lift from the caudal fin propulsion means that more power is generated through the caudal fin propulsion which decreases the drag as the marine vertebrate propagates through marine currents, and there is a less opposing force (Motani, 2002). The pelvic and anal fins work by creating vortices behind the caudal fin which change the pressure distribution over the caudal fin, but the caudal fin maintains its balance through an extensive range of angles of attack (Luthy et al., 2005; Shirgaonkar et al., 2008).

The same principles could be applied in designing the horizontal axis tidal turbine blades inspired by a curved caudal fin: the friction between seawater currents and turbine blades would be reduced, and the advancing turbine blades would rotate faster with less seawater current required to turn a turbine. Thus, biomimicry proves an excellent motivation to improve the tidal turbine efficiency, which is inspired by the wind turbine industry in this paper.

Figure 14 Biologically inspired application within various industries

\section{CONCLUSIONS}

This article should be of great interest to academics, researchers, engineers in tidal energy, and also other renewable energy consultants, as it brings together the concepts of the tidal energy physics, the ocean environment, hydrodynamics of horizontal axis tidal turbines, and bio-mimicry, to develop a novel HATT blade shape. Tidal energy conversion is based on the conversion of the kinetic energy available in tides with the use of horizontal axis tidal turbines to generate electricity through renewable energies. Tidal energy has a tiny reliance on fossil fuels and thus makes it a clean energy generating source. As tidal energy is a renewable source of energy, tides are very predictable with as much as $98 \%$ of accuracy. 
It also has the potential to fulfil a significant part of the energy requirements of the UK and the rest of the world.

A primary tidal turbine blade can be modelled using BEM theory and by choosing default NACA airfoil, and the hydrodynamic calculations based on the modelled parameters of the selected airfoil can be calculated to give a robust hydrodynamic blade. The ocean environment being incompressible has a tremendous effect on the overall efficiency of the designed tidal turbine, and is the most important topic to understand before tidal turbine blade design. The design variables that affect the overall efficiency of the horizontal axis tidal turbine system are chord lengths of airfoils, twist distribution, overall span of the blade, the angle of attack, the angular velocity of the blade, blade material, and the fluid velocity acting on the blade. According to the Betz limit, when a single turbine is installed in an infinite ocean, the maximum turbine efficiency cannot exceed $59.3 \%$.

Comprehensive analysis of biomimetic applications includes the design of Humpback whale turbine and other applications such as underwater propellers. The marine vertebrate synopsis discusses their swimming speeds, locomotion characteristics and their relation to the tidal turbine hydrodynamics. The study on the fish locomotion identifies the attributes of the swimming like lift based thrust, the locomotion driving factors: dorsal fins, caudal fins in propulsion, which enable the fish to be efficient even at low tidal velocities. Thus, it can be highlighted that a HATT blade designed by bio-mimicking a curved caudal fin shape would generate higher lift and power coefficients throughout the season i.e. for lower and higher tidal current velocities. This review of biological methods applied in the HATT design process is described to offer interesting conclusions which can be useful for future researchers in tidal energy conversion to solve renewable energy problems especially using tidal energy. 


\section{REFERENCES}

Abdulrahim, M. and Lind, R. (2004), "Flight testing and response characteristics of a variable gull-wing morphing aircraft", AIAA Paper, Vol. 5113, pp. 16-19.

Adrian, M.H. and Meeuwig, J.J. (2001), "Detecting lunar cycles in marine ecology: periodic regression versus categorical ANOVA", Marine Ecology Progress Series, Vol. 214, pp. 307-310.

Arns, A., Wahl, T., Haigh, I.D., Jensen, J. and Pattiaratchi, C. (2013), "Estimating extreme water level probabilities: a comparison of the direct methods and recommendations for best practise", Coastal Engineering, Elsevier, Vol. 81, pp. 51-66.

Ashwill, T.D., Kanaby, G., Jackson, K. and Zuteck, M. (2010), "Development of the sweep-twist adaptive rotor (STAR) blade", 48th AIAA Aerospace Sciences Meeting.

Bai, G., Li, W., Chang, H. and Li, G. (2016), "The effect of tidal current directions on the optimal design and hydrodynamic performance of a three-turbine system", Renewable Energy, Elsevier, Vol. 94, pp. 4854.

Benyus, J.M. (1997), Biomimicry, William Morrow New York.

Betz, A. (2014), Introduction to the Theory of Flow Machines, Elsevier.

Bhushan, B. (2009), "Biomimetics: lessons from nature--an overview”, Philosophical Transactions of the Royal Society of London A: Mathematical, Physical and Engineering Sciences, The Royal Society, Vol. 367 No. 1893, pp. 1445-1486.

Black \& Veatch Consulting Ltd. (2005), "Phase II - UK Tidal Stream Energy Resource Assessment", Black \& Veatch, London, Vol. 44 No. 0, p. 14.

Blunden, L.S. and Bahaj, A.S. (2006), "Initial evaluation of tidal stream energy resources at Portland Bill, UK”, Renewable Energy, Elsevier, Vol. 31 No. 2, pp. 121-132.

Bryden, I.G. and Couch, S.J. (2006), "ME1- marine energy extraction: tidal resource analysis", Renewable Energy, Elsevier, Vol. 31 No. 2, pp. 133-139.

Bryden, I.G., Couch, S.J., Owen, A. and Melville, G. (2007), "Tidal current resource assessment”, Proceedings of the Institution of Mechanical Engineers, Part A: Journal of Power and Energy, SAGE Publications, Vol. 221 No. 2, pp. 125-135.

Cai, Y.P., Huang, G.H., Yeh, S.C., Liu, L. and Li, G.C. (2012), “A modeling approach for investigating climate change impacts on renewable energy utilization", International Journal of Energy Research, Wiley Online Library, Vol. 36 No. 6, pp. 764-777.

Canter, N. (2008), "Humpback whales inspire new wind turbine technology", Tribology \& Lubrication Technology, Society of Tribologists and Lubrication Engineers, Vol. 64 No. 12, p. 10.

Chang, Y.-J., Brodziak, J., O-Malley, J., Lee, H.-H., DiNardo, G. and Sun, C.-L. (2015), "Model selection and multi-model inference for Bayesian surplus production models: a case study for Pacific blue and striped marlin", Fisheries Research, Elsevier, Vol. 166, pp. 129-139.

Chiang, W.-C., Musyl, M.K., Sun, C.-L., DiNardo, G., Hung, H.-M., Lin, H.-C., Chen, S.-C., et al. (2015), "Seasonal movements and diving behaviour of black marlin (Istiompax indica) in the northwestern Pacific Ocean", Fisheries Research, Elsevier, Vol. 166, pp. 92-102.

Cho, K.-J., Hawkes, E., Quinn, C. and Wood, R.J. (2008), "Design, fabrication and analysis of a body-caudal fin propulsion system for a microrobotic fish", Robotics and Automation, 2008. ICRA 2008. IEEE International Conference on, pp. 706-711.

Crawford, W.R. (2015), "Analysis of fortnightly and monthly tides", The International Hydrographic Review, Vol. 59 No. 1.

Department of Business, Enterprise and regulatory reform, Atlas of the UK marine renewable energy 
resource, BERR, London, U. (2008), "BERR Marine Atlas, 2008”.

Drucker, E.G. and Lauder, G. V. (2003), "Function of pectoral fins in rainbow trout: behavioral repertoire and hydrodynamic forces", Journal of Experimental Biology, The Company of Biologists Ltd, Vol. 206 No. 5, pp. 813-826.

Easton, M.C., Woolf, D.K. and Bowyer, P.A. (2012), "The dynamics of an energetic tidal channel, the Pentland Firth, Scotland", Continental Shelf Research, Elsevier, Vol. 48, pp. 50-60.

Eggleston, D.M. and Stoddard, F. (1987), "Wind turbine engineering design”, Van Nostrand Reinhold Co. Inc., New York, NY.

Elghali, S.E.B., Benbouzid, M.E.H. and Charpentier, J.F. (2007), "Marine Tidal Current Electric Power Generation Technology: State of the Art and Current Status", 2007 IEEE International Electric Machines Drives Conference, Vol. 2, pp. 1407-1412.

Di Felice, F., Felli, M., Liefvendahl, M. and Svennberg, U. (2009), "Numerical and experimental analysis of the wake behavior of a generic submarine propeller", Prism, Vol. 1 No. 8, p. 158.

Fish, F.E. (2009), “Biomimetics: determining engineering opportunities from nature”, Proc. SPIE.

Fish, F.E. and Battle, J.M. (1995), "Hydrodynamic design of the humpback whale flipper", Journal of Morphology, Wiley Online Library, Vol. 225 No. 1, pp. 51-60.

Fish, F.E., Weber, P.W., Murray, M.M. and Howle, L.E. (2011), “The tubercles on humpback whales' flippers: application of bio-inspired technology", Integrative and Comparative Biology, Soc Integ Comp Biol, Vol. 51 No. 1, pp. 203-213.

Flammang, B.E. (2014), "The fish tail as a derivation from axial musculoskeletal anatomy: an integrative analysis of functional morphology", Zoology, Elsevier, Vol. 117 No. 1, pp. 86-92.

Foreman, M.G.G. and Neufeld, E.T. (2015), "Harmonic tidal analysis of long time series", The International Hydrographic Review, Vol. 68 No. 1.

Gieseke Thomas. (2004), “Oscillating appendage for fin propulsion”, US6835108B1, available at: https://patents.google.com/patent/US6835108B1/en?q=oscillating\&q=appendage \&q=fin\&q=propulsion \#citedBy.

Gleiss, A.C., Jorgensen, S.J., Liebsch, N., Sala, J.E., Norman, B., Hays, G.C., Quintana, F., et al. (2011), "Convergent evolution in locomotory patterns of flying and swimming animals", Nature Communications, Nature Publishing Group, Vol. 2, p. 352.

Groves, G.W. and Reynolds, R.W. (1975), “An orthogonalized convolution method of tide prediction”, Journal of Geophysical Research, Wiley Online Library, Vol. 80 No. 30, pp. 4131-4138.

Han, J.-H., Lee, J.-S. and Kim, D.-K. (2009), "Bio-inspired flapping UAV design: a university perspective", SPIE Smart Structures and Materials+ Nondestructive Evaluation and Health Monitoring, p. 72951I-72951I.

Hoolihan, J.P. (2005), "Horizontal and vertical movements of sailfish (Istiophorus platypterus) in the Arabian Gulf, determined by ultrasonic and pop-up satellite tagging", Marine Biology, Springer, Vol. 146 No. 5, pp. 1015-1029.

Iwasaki, S., Isobe, A. and Miyao, Y. (2015), "Fortnightly atmospheric tides forced by spring and neap tides in coastal waters", Scientific Reports, Nature Publishing Group, Vol. 5.

Iyer, A.S., Couch, S.J., Harrison, G.P. and Wallace, A.R. (2013), "Variability and phasing of tidal current energy around the United Kingdom", Renewable Energy, Elsevier, Vol. 51, pp. 343-357.

James, S.C., Seetho, E., Jones, C. and Roberts, J. (2010), "Simulating environmental changes due to marine hydrokinetic energy installations", OCEANS 2010 MTS/IEEE SEATTLE, pp. 1-10.

Jayne, B.C., Lozada, A.F. and Lauder, G. V. (1996), "Function of the dorsal fin in bluegill sunfish: motor patterns during four distinct locomotor behaviors", Journal of Morphology, Philadelphia, Pa.: Wistar 
Institute of Anatomy and Biology,[1931-, Vol. 228 No. 3, pp. 307-326.

Keck, H. and Sick, M. (2008), "Thirty years of numerical flow simulation in hydraulic turbomachines", Acta Mechanica, Springer, Vol. 201 No. 1-4, pp. 211-229.

Konadu, D.D., Mourão, Z.S., Allwood, J.M., Richards, K.S., Kopec, G., McMahon, R. and Fenner, R. (2015), "Land use implications of future energy system trajectories - The case of the UK 2050 carbon plan”, Energy Policy, Elsevier, Vol. 86, pp. 328-337.

Kraus, R.T., Wells, R.J.D. and Rooker, J.R. (2011), "Horizontal movements of Atlantic blue marlin (Makaira nigricans) in the Gulf of Mexico", Marine Biology, Springer, Vol. 158 No. 3, pp. 699-713.

Larwood, S. and Zuteck, M. (2006), "Swept wind turbine blade aeroelastic modeling for loads and dynamic behavior", AWEA Windpower, Citeseer, pp. 1-17.

Leffler, K.E. and Jay, D.A. (2009), "Enhancing tidal harmonic analysis: Robust (hybrid L1/L2) solutions", Continental Shelf Research, Elsevier, Vol. 29 No. 1, pp. 78-88.

Lenarz, W.H. and Nakamura, E.L. (1972), "Analysis of length and weight data on three species of billfish from the western Atlantic Ocean", Proceedings of the International Billfish Symposium, Kailua-Kona, Hawaii, pp. 9-12.

Leung, K. (2014), “Investigation of Wind Turbine Blades with Tubercles.”, Advanced Materials Research, No. 1051.

Liu, J. and Hu, H. (2005), "Mimicry of sharp turning behaviours in a robotic fish", Proceedings of the 2005 IEEE International Conference on Robotics and Automation, pp. 3318-3323.

Lowry, M., Williams, D. and Metti, Y. (2007), "Lunar landings-Relationship between lunar phase and catch rates for an Australian gamefish-tournament fishery", Fisheries Research, Elsevier, Vol. 88 No. 1, pp. $15-23$.

Luthy, S.A., Cowen, R.K., Serafy, J.E. and McDowell, J.R. (2005), “Toward identification of larval sailfish (Istiophorus platypterus), white marlin (Tetrapturus albidus), and blue marlin (Makaira nigricans) in the western North Atlantic Ocean", Fishery Bulletin, Vol. 103 No. 4, pp. 588-600.

Magagna, D. and Uihlein, A. (2015), "Ocean energy development in Europe: Current status and future perspectives", International Journal of Marine Energy, Elsevier, Vol. 11, pp. 84-104.

Malki, R., Williams, A.J., Croft, T.N., Togneri, M. and Masters, I. (2013), “A coupled blade element momentum--Computational fluid dynamics model for evaluating tidal stream turbine performance", Applied Mathematical Modelling, Elsevier, Vol. 37 No. 5, pp. 3006-3020.

Manwell, J.F., McGowan, J.G. and Rogers, A.L. (2010), Wind Energy Explained: Theory, Design and Application, John Wiley \& Sons.

Martin-Short, R., Hill, J., Kramer, S.C., Avdis, A., Allison, P.A. and Piggott, M.D. (2015), "Tidal resource extraction in the Pentland Firth, UK: Potential impacts on flow regime and sediment transport in the Inner Sound of Stroma", Renewable Energy, Elsevier, Vol. 76, pp. 596-607.

Matte, P., Secretan, Y. and Morin, J. (2014), "Temporal and spatial variability of tidal-fluvial dynamics in the St. Lawrence fluvial estuary: An application of nonstationary tidal harmonic analysis", Journal of Geophysical Research: Oceans, Wiley Online Library, Vol. 119 No. 9, pp. 5724-5744.

MCT, M.C.T.L. (2008), “SeaGen Tidal Energy System Reaches Full Power - 1.2MW”, available at: http://www.marineturbines.com/SeaGen-Technology/Performance (accessed 1 April 2013).

Michaels, S.C., Moses, K.C., Bachmann, R.J., Hamilton, R., Pena-Francesch, A., Lanba, A., Demirel, M.C., et al. (2015), "Biomimicry of the Manduca Sexta Forewing Using SRT Protein Complex for FWMAV Development", Conference on Biomimetic and Biohybrid Systems, pp. 86-91.

Morandi, B., Di Felice, F., Costanzo, M., Romano, G.P., Dhomé, D. and Allo, J.C. (2016), "Experimental investigation of the near wake of a horizontal axis tidal current turbine", International Journal of 
Marine Energy, Elsevier, Vol. 14, pp. 229-247.

Motani, R. (2002), "Scaling effects in caudal fin propulsion and the speed of ichthyosaurs", Nature, Nature Publishing Group, Vol. 415 No. 6869, pp. 309-312.

Mycek, P., Gaurier, B., Germain, G., Pinon, G. and Rivoalen, E. (2013), "Numerical and experimental study of the interaction between two marine current turbines", arXiv Preprint arXiv:1310.4921.

Rayson, M.D., Gross, E.S. and Fringer, O.B. (2015), "Modeling the tidal and sub-tidal hydrodynamics in a shallow, micro-tidal estuary", Ocean Modelling, Elsevier, Vol. 89, pp. 29-44.

Sagong, W., Jeon, W.-P. and Choi, H. (2013), "Hydrodynamic characteristics of the sailfish (Istiophorus platypterus) and swordfish (Xiphias gladius) in gliding postures at their cruise speeds", PloS One, Public Library of Science, Vol. 8 No. 12, p. e81323.

Salumäe, T. and Kruusmaa, M. (2011), "A flexible fin with bio-inspired stiffness profile and geometry", Journal of Bionic Engineering, Elsevier, Vol. 8 No. 4, pp. 418-428.

Sfakiotakis, M., Lane, D.M. and Davies, J.B.C. (1999), "Review of fish swimming modes for aquatic locomotion”, IEEE Journal of Oceanic Engineering, IEEE, Vol. 24 No. 2, pp. 237-252.

Shi, W., Rosli, R., Atlar, M., Norman, R., Wang, D. and Yang, W. (2016), "Hydrodynamic performance evaluation of a tidal turbine with leading-edge tubercles", Ocean Engineering, Elsevier, Vol. 117, pp. 246-253.

Shi, W., Wang, D., Atlar, M., Guo, B. and Seo, K. (2015), "Optimal design of a thin-wall diffuser for performance improvement of a tidal energy system for an AUV", Ocean Engineering, Elsevier, Vol. 108, pp. 1-9.

Shields, M.A., Dillon, L.J., Woolf, D.K. and Ford, A.T. (2009), "Strategic priorities for assessing ecological impacts of marine renewable energy devices in the Pentland Firth (Scotland, UK)", Marine Policy, Elsevier, Vol. 33 No. 4, pp. 635-642.

Shirgaonkar, A.A., Curet, O.M., Patankar, N.A. and MacIver, M.A. (2008), "The hydrodynamics of ribbonfin propulsion during impulsive motion", Journal of Experimental Biology, The Company of Biologists Ltd, Vol. 211 No. 21, pp. 3490-3503.

Standen, E.M. and Lauder, G. V. (2007), "Hydrodynamic function of dorsal and anal fins in brook trout (Salvelinus fontinalis)", Journal of Experimental Biology, The Company of Biologists Ltd, Vol. 210 No. 2, pp. 325-339.

Su, N.-J., Sun, C.-L., Tai, C.-Y. and Yeh, S.-Z. (2016), "LENGTH-BASED ESTIMATES OF GROWTH AND NATURAL MORTALITY FOR BLUE MARLIN (Makaira nigricans) IN THE NORTHWEST PACIFIC OCEAN", Journal of Marine Science and Technology, Vol. 24 No. 2, pp. 370-378.

Tedds, S.C., Owen, I. and Poole, R.J. (2014), "Near-wake characteristics of a model horizontal axis tidal stream turbine", Renewable Energy, Elsevier, Vol. 63, pp. 222-235.

Tokić, G. and Yue, D.K.P. (2012), "Optimal shape and motion of undulatory swimming organisms", Proceedings of the Royal Society of London B: Biological Sciences, The Royal Society, Vol. 279 No. 1740, pp. 3065-3074.

Uihlein, A. and Magagna, D. (2016), "Wave and tidal current energy--A review of the current state of research beyond technology", Renewable and Sustainable Energy Reviews, Elsevier, Vol. 58, pp. $1070-1081$.

Vennell, R. (2013), “Exceeding the Betz limit with tidal turbines”, Renewable Energy, Elsevier, Vol. 55, pp. 277-285.

Vu, T.C. and Retieb, S. (2002), "Accuracy assessment of current CFD tools to predict hydraulic turbine efficiency hill chart", Proceedings of the 21st IAHR Symposium on Hydraulic Machinery and Systems, Vol. 1, pp. 193-198.

Watanabe, Y. and Sato, K. (2008), "Functional dorsoventral symmetry in relation to lift-based swimming in 
the ocean sunfish Mola mola", PLoS One, Public Library of Science, Vol. 3 No. 10, p. e3446.

Waters, S. and Aggidis, G. (2016), "Tidal range technologies and state of the art in review", Renewable and Sustainable Energy Reviews, Elsevier, Vol. 59, pp. 514-529.

Windsor, S.P., Norris, S.E., Cameron, S.M., Mallinson, G.D. and Montgomery, J.C. (2010a), “The flow fields involved in hydrodynamic imaging by blind Mexican cave fish (Astyanax fasciatus). Part I: open water and heading towards a wall", Journal of Experimental Biology, The Company of Biologists Ltd, Vol. 213 No. 22, pp. 3819-3831.

Windsor, S.P., Norris, S.E., Cameron, S.M., Mallinson, G.D. and Montgomery, J.C. (2010b), "The flow fields involved in hydrodynamic imaging by blind Mexican cave fish (Astyanax fasciatus). Part II: gliding parallel to a wall”, Journal of Experimental Biology, The Company of Biologists Ltd, Vol. 213 No. 22, pp. 3832-3842.

Yuce, M.I. and Muratoglu, A. (2015), "Hydrokinetic energy conversion systems: A technology status review", Renewable and Sustainable Energy Reviews, Elsevier, Vol. 43, pp. 72-82.

Zetler, B., Cartwright, D. and Berkman, S. (2015), "Some comparisons of response and harmonic tide predictions", The International Hydrographic Review, Vol. 56 No. 2. 


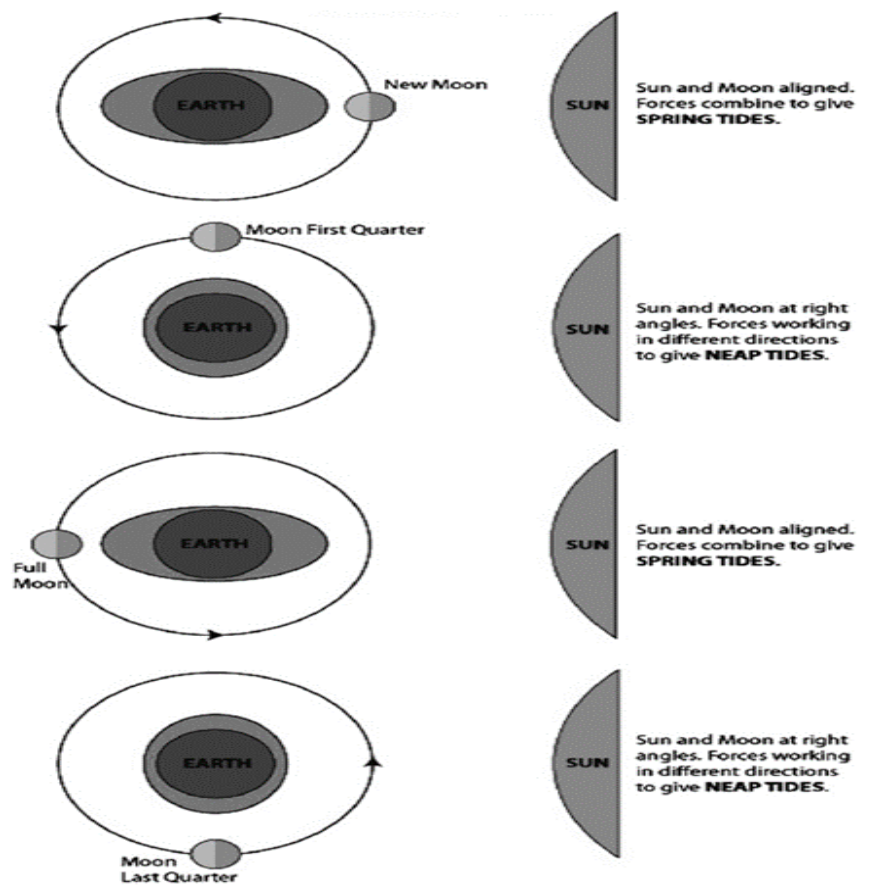

Figure 1 Generation of the neap and spring tides (James et al., 2010)

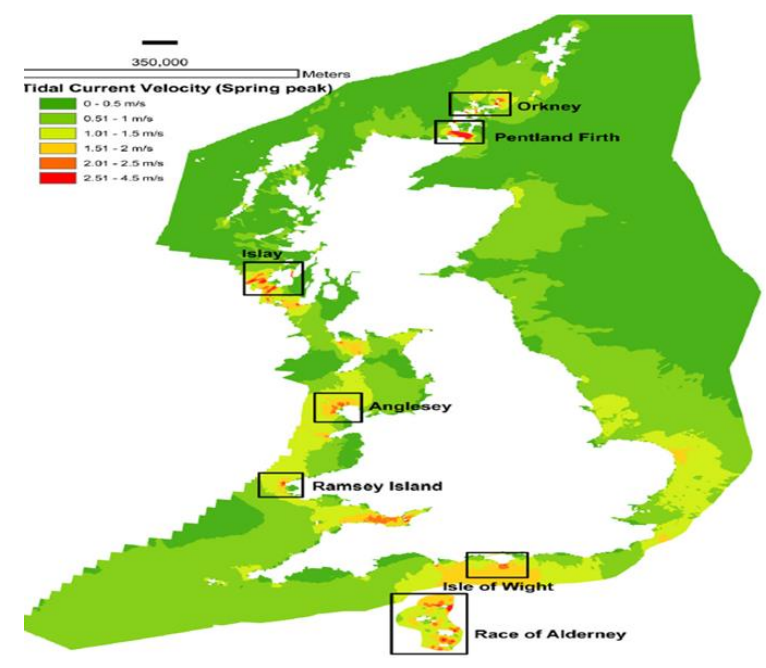

Figure 2 Mean Spring tide current velocities and specific regions of tidal sites (Department of Business, Enterprise and regulatory reform, Atlas of the UK marine renewable energy resource, BERR, London, 2008). 


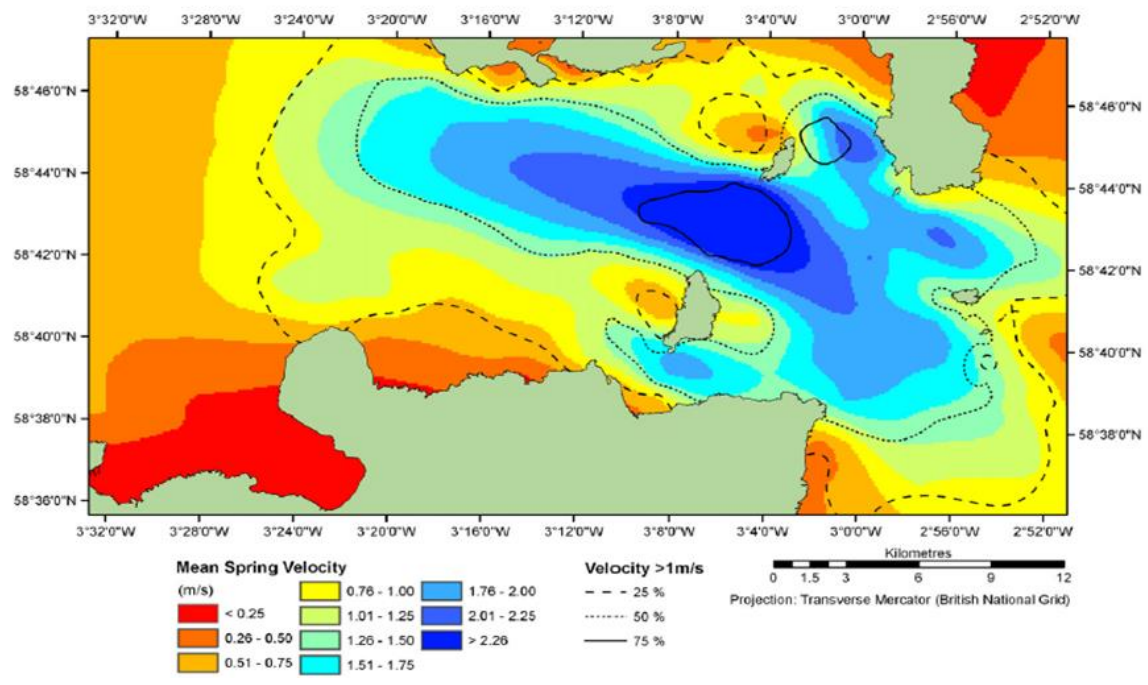

Figure 3 the tidal current velocities in mean spring tide for the Pentland Firth, Scotland area (Shields et al., 2009)
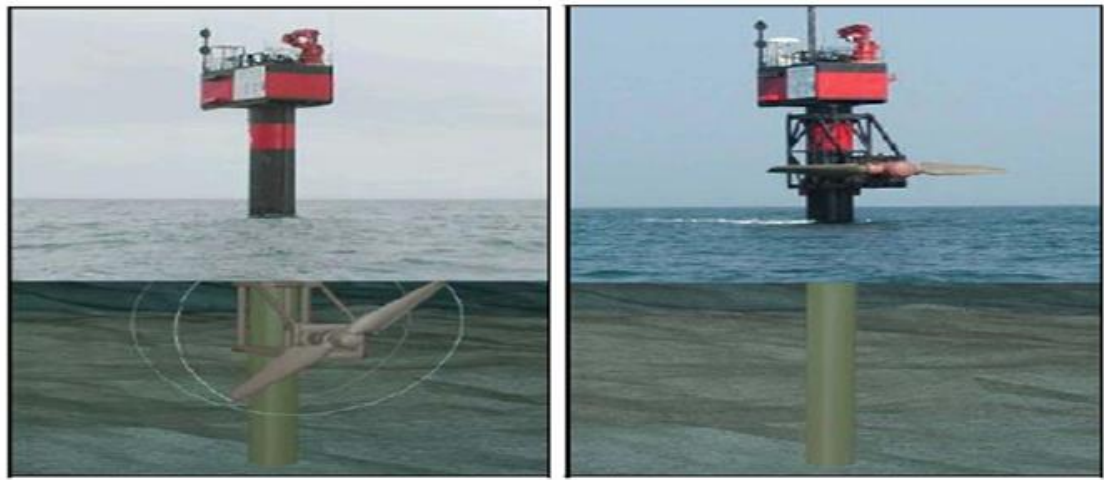

Figure 4 Seaflow turbine system by MCT (MCT, 2008)

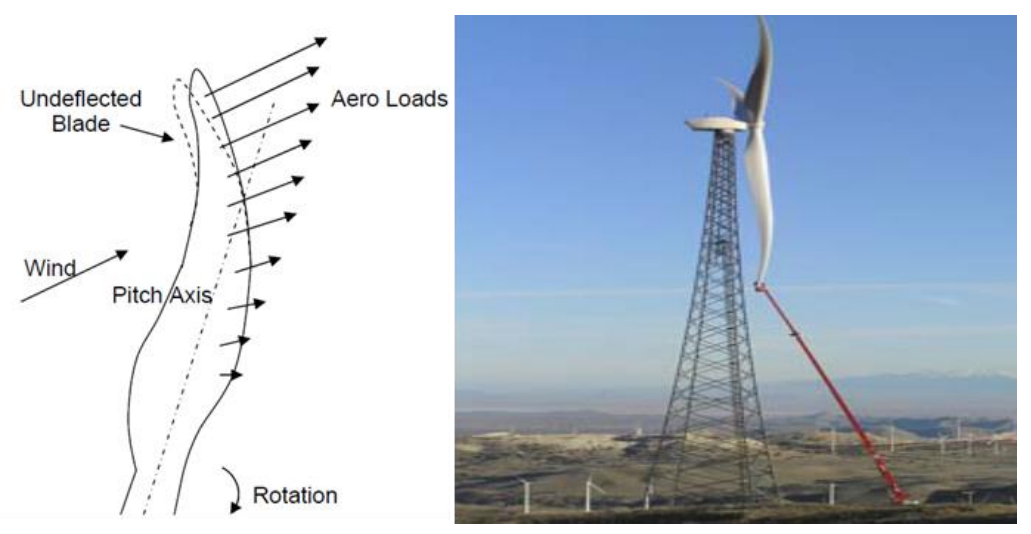

Figure 15.1 Swept blade concept (after Ashwill et al., 2010), Figure 5.2 Manufactured STAR blades for flight testing (Larwood and Zuteck, 2006) 


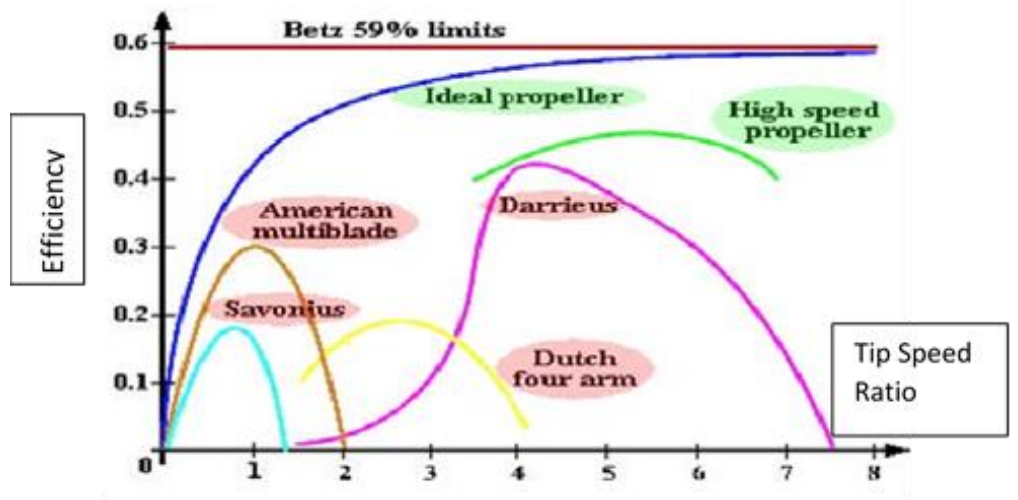

Figure 16 various efficiency limits of water turbines (after Vu and Retieb, 2002)

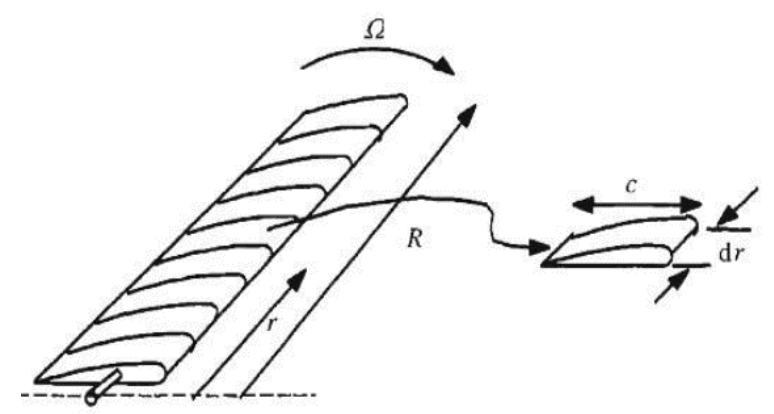

Figure 17 Illustration of the blade sections (after Manwell et al., 2010)

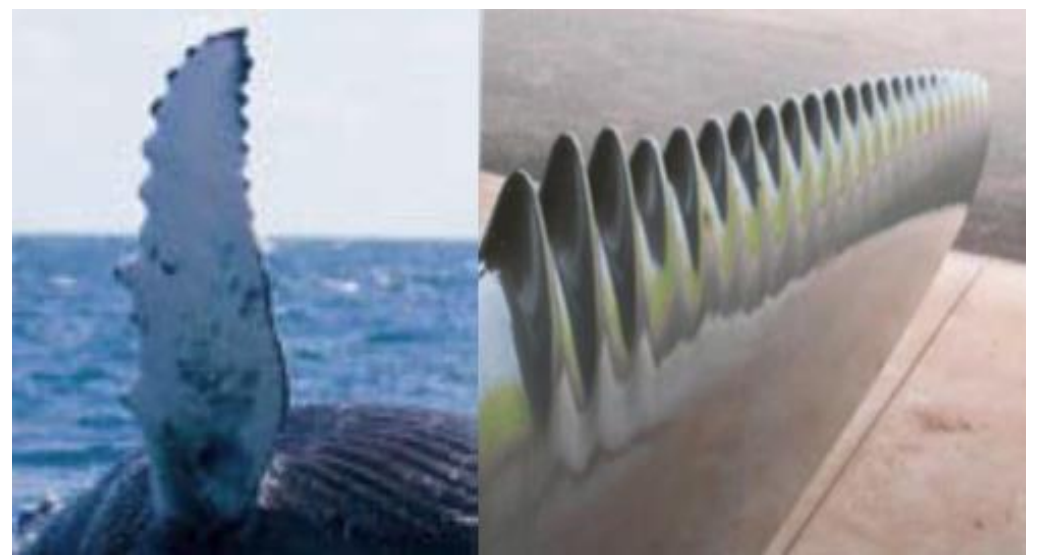

Figure 9.1 Humpback whale pectoral flippers, and Figure 9.2 Manufactured adapted tubercles on the leading edge of WhalePower wind turbine blade (Fish et al., 2011). 


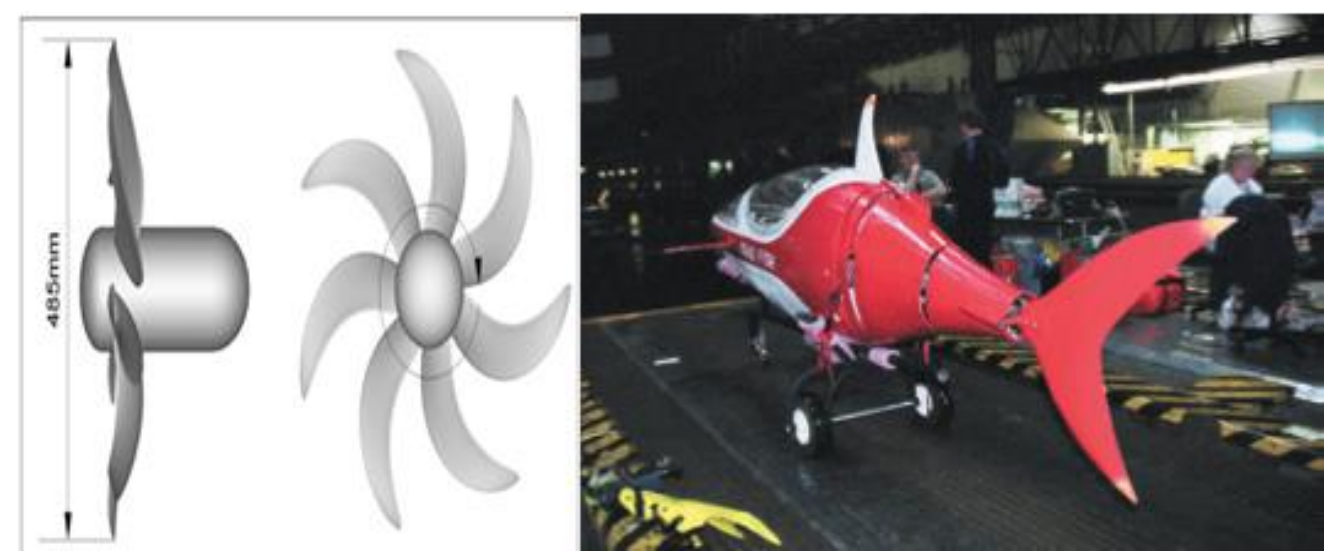

Figure 10.1 seven blades conventional propeller (Di Felice et al., 2009), and Figure 10.2 the Faux Fish fish tailfin propeller (Gieseke Thomas, 2004)

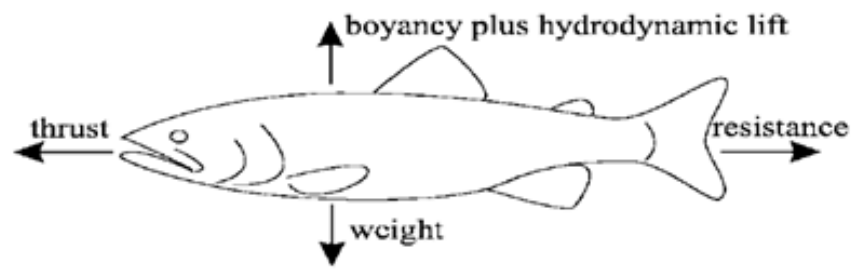

(a)

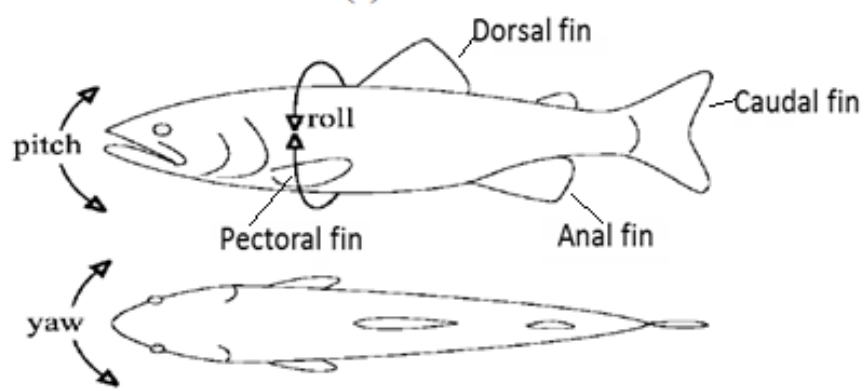

(b)

Figure 11 the locomotion forces acting on the fish while swimming (Sfakiotakis et al., 1999) 

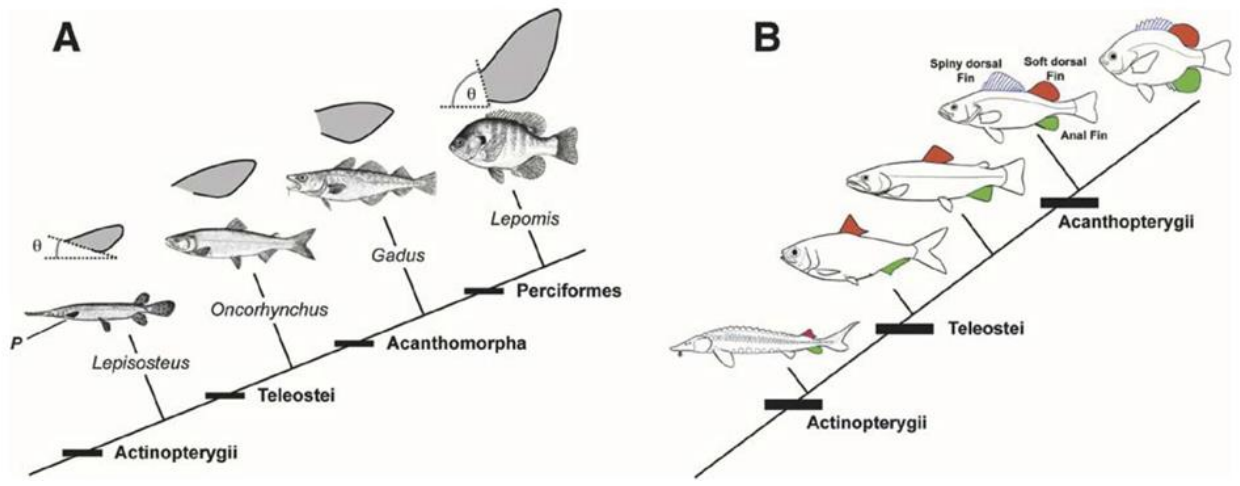

Figure 12 the evolution of the pectoral (A), and dorsal (B) fins in different species (Jayne et al., 1996)

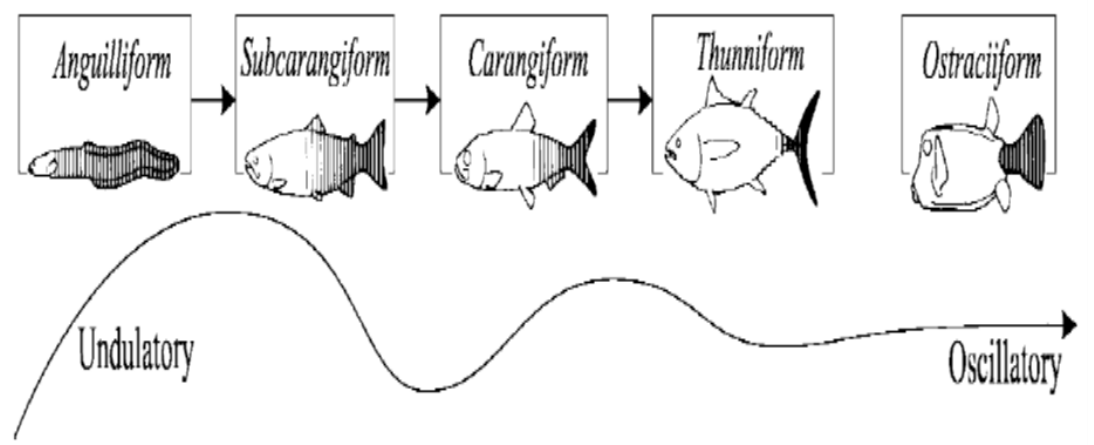

Figure 13 Different swimming modes of fishes (Sagong et al., 2013) 


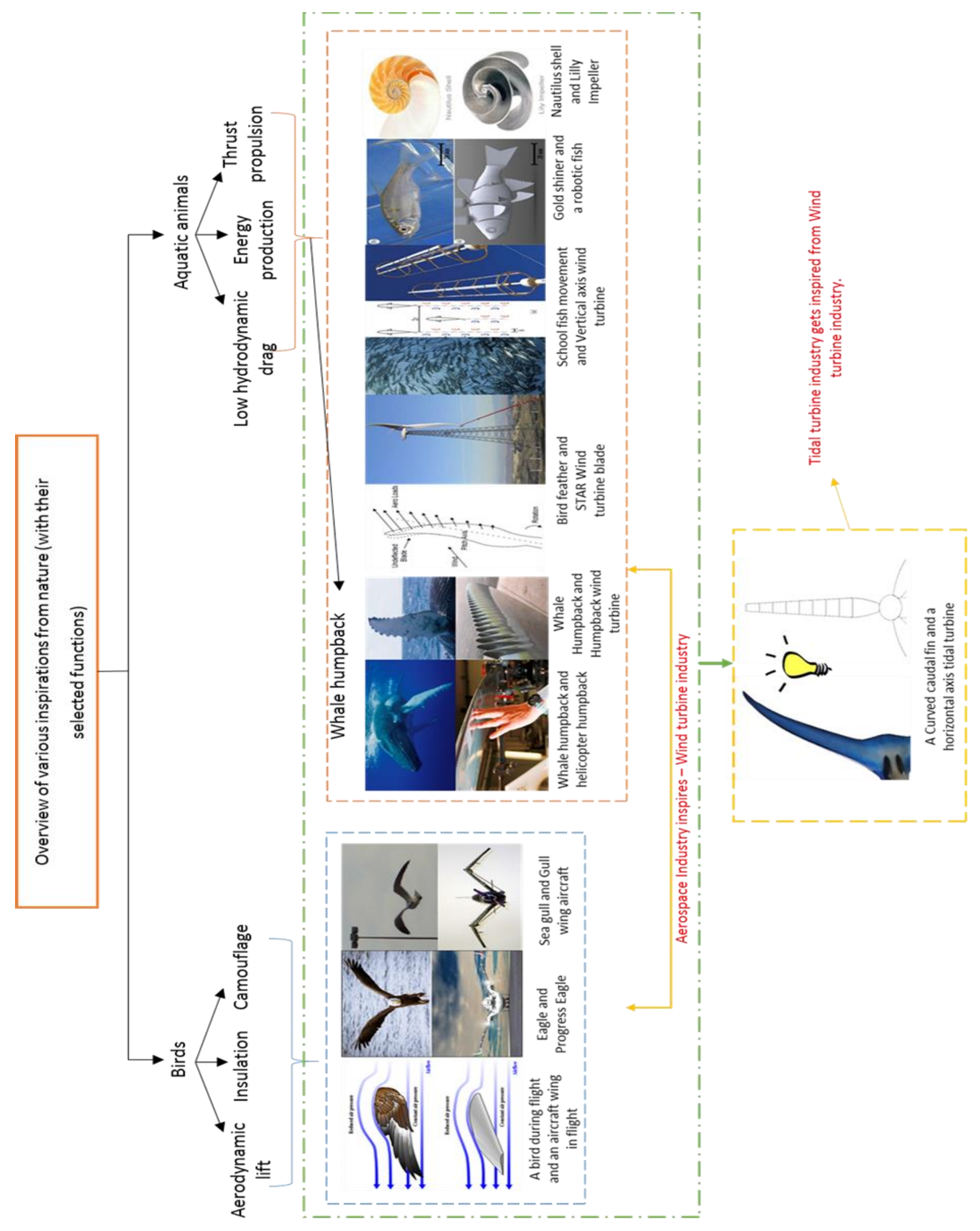

Figure 14 Biologically inspired application within various industries 